\title{
Support of physicians doing research at University of Medicine and Dentistry of New Jersey-School of Osteopathic Medicine
}

GARY GOLDBERG

Camden, New Jersey
The activation and support of clinical research at a college of osteopathic medicine requires a clearly expressed institutional commitment and structure. The Research Division at the University of Medicine and Dentistry of New Jersey-School of Osteopathic Medicine (UMDNJ-SOM) has been planning and managing such a support program over the last 6 years. This presentation examines the assumptions and progress of this program at both the conceptual and operating levels. I believe that these approaches described can be used as guides and models by other colleges.

The Research Division was set up in 1982 under the associate dean for research as a mechanism to facilitate the efforts of the faculty and staff at UMDNJ-SOM in seeking outside support for their research, teaching, and service programs. The emphasis constantly has been on providing the staff and support services required to develop research ideas into fundable applications. As soon as one proposal is completed and submitted by the principal investigator or program director, the Division moves on to his/her next proposal. The Division has been doing this concurrently with as many as 85 to 90 persons. It relies on the principal investigator or program director for the scholarly impetus and the knowledge and experience in the special area of biomedicine that underlie a successful proposal.

In its first 6 years' experience, the Research Division, working together primarily with the laboratory scientists, has found that the most effective approach to staffing research development is one that focuses not on outcome (grant awards) but rather on process (multiple concurrent applications, networking with scientific colleagues/collaborators and grant program officers, and revising and resubmitting rejected proposals). This conclusion is based on two kinds of data, as follows:

(1) observation that SOM faculty members who get the most and longer-term grant awards are those who submit the most applications (and get the most rejections as well); and (2) research sponsored by the National Institutes of Health (NIH), ${ }^{1}$ which indicates that the applications-to-awards ratio is critical.

With this in mind, the Division will continue to encourage faculty, staff, and administrators to recognize that a successful record of performance is measured by the number of applications submitted and/or revised rather than the number of grants awarded.

The major goal of the Research Division over the next few years is to help the medical school's clinical faculty members to activate their research ideas and develop them into fundable programs. To this end, the Division plans to continue using the techniques and approaches found effective for the basic science faculty. The following section highlights some of the ways clinical faculty research is staffed and supported.

\section{Activating clinical faculty research}

Within the Division, clinical faculty research is defined as research performed by faculty members who are involved with patient care (including D.O.s, M.D.s, Ph.D.s, and Ed.D.s). A broad range of approaches to activating such research has been developed and evaluated by the Division over the last few years. Although some of these approaches involve the transfer of methods found to be effective and productive for the basic science faculty, ${ }^{2-5}$ additional ones are modeled on successful programs from other medical schools. Still other approaches are new, and these may be developed further together with interested faculty members.

All these approaches focus on helping the faculty to turn their research ideas into fundable proposals and are based on the notion of addressing the expressed needs of individual faculty-investigators. That is, once a faculty member states a need in the area of research development or grant-seeking, the 
Division begins finding ways to meet that need. The approaches employed are listed in order hereafter, roughly according to what is considered their ease of accomplishment. The Division anticipates building its efforts upon the resources already available within the medical school and upon the successes clinical faculty members have already achieved. (This order, however, may vary in different departments of the medical school and at other institutions in light of their own operating circumstances and resources.)

\section{Seed grants targeted for start-up research projects developed by individual clinical faculty members}

\section{a. Internal}

(1) SOM's Biomedical Research Support Grant/ Research Reinvestment Fund (BRSG/RRF) program. The BRSG component is an award from NIH based on the dollar amount of NIH grants awarded to SOM investigators during the prior year. The $\mathrm{RRF}$ is a percentage of the research grant indirect cost recoveries received by SOM that has been dedicated to this purpose by the dean.

\section{Past/current awardees:}

-Raymond A. Adelizzi, D.O. (Medicine)-Control of monocyte interleukin-1 production in patients with systemic lupus erythematosus

-Daniel H. Belsky, D.O. (Obstetrics/ Gynecology)-Survey of gynecologic care of the elderly in nursing homes

Jane L. Coleman, M.D. (Pediatrics) and Gregory J. Downing, D.O. (Pediatrics resident)-Effects of lipid infusion on glucose metabolism in pre-term neonates

-John W. Fitzharris Jr., D.O. (Medicine)-Videotaping of medical students' performance of histories and physical examinations

-Nathan Freed, D.O. (Medicine)-Evaluation of Living Effectively With Cancer support program -Thomas F. Morley, D.O. (Medicine)-Comparison of $\beta$-adrenergic agents delivered via nebulizer versus metered dose inhaler with InspirEase for the treatment of hospitalized asthmatic patients

—Jerome J. Platt, Ph.D. (Psychiatry)-Functional capacity and interpersonal cognitive problem-solving in the elderly

-David Rissmiller, D.O. (Psychiatry)—Computerassisted psychiatric interviewing to improve the validity and reliability of DSM-III, axis-II (personality) disorder diagnoses

-Harvey Rothman, D.O. (Medicine)-Computerized tumor registry
-Shekeeb Sufian, M.D. (Surgery)Aminoglycoside nephrotoxicity

-Theodore Weinberg, D.O. (Medicine)-Depression and glycemia in diabetes

(2) Foundation of UMDNJ grant program. The primary purpose of this grant program is to encourage research by young faculty who do not yet have a track record to attract significant funding from other sources. Therefore, priority is given to faculty of lower rank, those who have recently joined the faculty, and those whose prior research experience might not yet enable them to be competitive with their peers for national grant programs.

\section{Past/current awardees:}

-Dr. Platt-Interpersonal cognitive problem-solving as a prevention/intervention for adolescents at risk for drug abuse

-Robert Steer, Ed.D. (Psychiatry)-Depression, hopelessness, dysfunctional attitudes, and suicidal ideation in psychiatric patients

\section{b. External}

(1) Family Health Foundation of America research stimulation grants. These grants are targeted for departments of family practice.

(2) NIH Small Grants program. These grants are intended for new investigators who wish to carry out small clinical research projects or to analyze existing clinical data.

\section{Clinical trials funded by the pharmaceutical and medical device industries}

These studies are particularly appropriate for new investigators because a detailed protocol is designed and provided by the study sponsor, and investigators are trained and monitored throughout the course of the study by the sponsor's field staff as well. Many study sponsors will pay for an office nurse and clerk/secretary to help the principal investigator administer the study on a day-to-day basis. Also, they sponsor office functions as the central clearinghouse for data acquisition, storage, and analysis for the different study sites and will usually support the individual investigators in publishing the results of the study.

\section{a. New (experimental, investigational) drug and medical device studies}

Twenty SOM physicians in the departments of family practice, medicine, obstetrics/gynecology, and pediatrics perform this kind of research. In addi- 
tion, SOM physicians in the departments of psychiatry and surgery are now negotiating with study sponsors to obtain their first clinical trial studies.

\section{b. Consulting opportunities}

The Division is now seeking to expand upon the clinical trials approach to research activation by arranging for faculty members to serve as consultants to pharmaceutical and biotechnology startup companies on the design of their clinical protocols and on other clinical aspects of drug and medical device development. The Research Division attempts to identify these kinds of opportunities through UMDNJ's Associate Vice President for University-Industry Affairs, UMDNJ's patent lawyer, NIH's Small Business Innovation Research grant program, membership in several local and regional biotechnology consortia, and its network of professional interest contacts with individual industry scientists and research managers.

Frederick G. Meoli, D.O. (Surgery) and Dr. Freed have expressed interest in working with SRI-Sarnoff Research Institute of Princeton, New Jersey, on its research into the biomedical applications of microwaves. Examples of such applications might be to stimulate blood flow in certain vascular conditions and to produce hyperthermia as an adjuvant to cancer chemotherapy.

Dr. Rothman has expressed interest in working with two small biotechnology start-up companies on their research and development efforts. In the one case, the effort involves a wearable non-gravity-dependent infusion device for the delivery of continuous cancer chemotherapy; in the other, cell growth chambers for cancer chemotherapy drug screening.

\section{Research projects based on ongoing clinical service programs and their patient panels}

Current examples of this approach include research associated with the Fetal Loss Program, the Human Genetics Program (Michael McCormack, Ph.D.) in the Department of Pediatrics, and with the Osteoporosis Diagnostic and Treatment Center (Dr. Adelizzi) in the Department of Medicine. Planned clinical programs taking this approach include the Gestational Diabetes Screening and Treatment Center (Joseph Bottalico, D.O., George H. Davis, D.O., and Peter Vasilenko, Ph.D.) in the Department of Obstetrics/Gynecology and the AIDS testing laboratory (David Condoluci, D.O.) in the Department of Medicine.

\section{Therapeutic research programs that}

\section{generate fees for the faculty practice} component of a physician's salary

Experimental cancer chemotherapy in cases where the patient is refractory to approved drugs would be such a research program. Dr. Freed's participation in the Eastern Cooperative Oncology Group (ECOG) and Dr. Rothman's participation in the Mid-Atlantic Oncology Program (MAOP) are examples of this approach. (Although third party payers will not generally cover the costs of research, they usually will do so when an individual patient has not responded to standard therapy and the only course of treatment left is a research procedure.)

\section{Participation on the medical school's Research Committee, Institutional Review Board/Committee for the Protection of Human Subjects (IRB/CPHS), and BRSG/ RRF peer review panel}

This kind of experience acquaints new investigators with research and grant-seeking activities and resources (for example, personnel, equipment, and patient panels) throughout the medical school and thereby can stimulate the activation of their own research ideas. Faculty members may serve on the IRB/CPHS and BRSG/RRF committees on the basis of their clinical insight and need not have had prior research activity at SOM to be eligible.

\section{Participation on outside task forces and committees}

Like participation on medical school committees, this kind of experience acquaints new investigators with research and grant-seeking activities and resources throughout the region, usually in more specialized areas of interest, and thereby can stimulate the activation of their own research ideas. In some cases, faculty members may serve on outside committees on the basis of their clinical experience and need not have had prior research activity at SOM to be eligible.

\section{Examples}

Martin A. Finkel, D.O. (Pediatrics) is a member of the New Jersey Children's Trust Fund, which was established by the state legislature in 1985 to prevent child abuse. He also spearheaded the development of the Camden County Coalition Against Sexual Abuse of Children and now leads it. Dr. McCormack has served as the chairman of the Task Force on the Prevention of Mental Retardation from Biomedical Causes of the Governor's Council on the Prevention of Mental Retardation. 


\section{Research collaborations with medical school laboratory and social scientists}

An example of this approach would be getting support with study design and data analysis questions or providing human tissue samples for laboratory analysis.

\section{Current projects}

a. Dr. Adelizzi and Eugene Mochan, Ph.D., D.O. (Family Practice)-Dr. Adelizzi's BRSG/RRF project

b. Dr. Belsky and Mindy Widman, DSW (Psychiatry)-Survey of gynecologic care of the elderly in nursing homes

c. Thomas A. Cavalieri, D.O., and Lloyd Forman, Ph.D. (both Medicine)-(1)Plasma levels of $\beta$-endorphin in young and aged human males during the morning hours; and (2) $\beta$-endorphin levels in the cerebrospinal fluid and plasma of elderly patients presenting with acute confusion

d. H. Timothy Dombrowski, D.O., and Dr. Forman (both Medicine)-Hemoglobin $\mathrm{A}_{1 \mathrm{C}}$ as an indicator of diabetes in the elderly

e. Dr. Freed and Dr. Vasilenko-The role of iron replacement in the treatment and correction of idiopathic menorrhagia

f. Louis A. Papa, D.O. (Medicine) and William Santamore, Ph.D. (Graduate Hospital of the University of Pennsylvania)-Theoretical model for ventricular interdependence

g. Andrew A. Pecora, D.O., and Carl Hock, Ph.D. (both Medicine)-The detection, treatment, and cause of collagenous colitis

h. The three Ph.D. scientists in the Department of Obstetrics/Gynecology (Matthew J. Freund, Ph.D., Theresa Scholl, M.P.H., Ph.D., and Dr. Vasilenko) have formed a team to meet regularly with the clinicians in the department to help them develop and activate their research ideas.

\section{Research collaborations with successful clinical investigators at other institutions}

\section{Current project}

Dr. Freed is exploring the potential for joint oncology research with David Goldenberg, M.D. (UMDNJ-Center for Molecular Medicine and Immunology) in radioimmunodiagnostics, radioimmunotherapy, and monoclonal antibodies.

\section{Planned projects}

Thomas Santucci, Jr., D.O. (Pediatrics) intends to pursue research into pulmonary implications of gastroesophageal reflux during his faculty renewal leave later this year at Duke University. Joellyn Ross, Ph.D., (Family Practice) intends to collaborate with Lawrence Fisher, Ph.D. (University of California at San Francisco/Veterans Administration Medical Center, Fresno, California) by incorporating the results of his research on the effects of family dynamics on health status into a training module for family practice residents.

\section{Participation in multi-institutional research protocols}

Like clinical trials, these kinds of studies are attractive for new investigators because a detailed protocol is designed and provided by a coordinating or steering panel and funds are sometimes available to pay for an office nurse and clerk/secretary to help administer the study on a day-to-day basis. In addition, the coordinating office usually functions as the central clearinghouse for data acquisition, storage, and analysis for the different study sites and will usually support the individual investigators as well in publishing the results of the study.

\section{Current projects}

a. The Low Back Pain Research Project of the AOA Bureau of Research

b. Research projects organized by the Osteopathic Surgical Research Committee of the American College of Osteopathic Surgeons

\section{Participation in medical school task force, Center of Excellence, and special initiative research projects*}

Each of these focuses on one primary theme such as addiction treatment research, fetal and maternal health, forensic psychology/psychiatry, gerontology, osteopathic medical treatment, and osteopathic wellness. Each program is staffed by a group of faculty and support personnel who dedicate a major portion of their time and effort to it. Usually, each program is activated through SOM seed dollars (for example, over a 5-year declining budget) until sufficient external income can be generated through clinical fees and grants.

\section{Current projects}

Drs. Cavalieri and Forman are activating clinical research on aging in their respective roles as director and research coordinator for the Gerontology *Centers of Excellence and special initiatives are interdepart-
mental. 
Center of Excellence. Dr. Platt is activating clinical research in his role as director of both the Addiction Treatment Research and the Forensic Psychology/ Psychiatry Centers of Excellence. He is accomplishing this now together with current faculty members and also anticipates recruiting new faculty, some of whose positions will be dedicated entirely to research. In addition, both Centers of Excellence have training slots, funded by UMDNJ, for pre- and postdoctoral clinical research fellows.

\section{Participation on University and medical school research grant-writing teams}

Dr. Freed is a member of UMDNJ's Cancer Committee.

\section{Supervision of residents, medical students, and nurses on their own clinical research projects}

\section{a. Past projects}

(1) Dr. Nathan Freed, and James Lavis, D.O. (Obstetrics/Gynecology) have supervised nursing students' research projects at Kennedy Memorial Hospitals/Univeristy Medical Center (KMH/UMC) in Stratford.

(2) William Vilensky, D.O. (Family Practice) has supervised a medical student's research into the training needs of Camden County police departments in the area of recognizing and managing drug and alcohol abusers.

(3) Barbara Caton, D.O. (Family Practice resident)-Efficacy of sucralfate in enema form for the treatment of ulcerative proctitis and ulcerative proctosigmoiditis (Faculty sponsor, Dr. Pecora).

\section{b. Current project}

(1) David Beatty (third-year SOM student)-Denial and enabling in cigarette smoking (Faculty sponsor, Dr. Mochan)

(2) Dr. Downing (Pediatrics residents)-Effects of lipid infusion on glucose metabolism in pre-term neonates (Faculty sponsor, Dr. Coleman)

\section{c. Department of Obstetrics/Gynecology Residents Research Program}

Under the direction of the department chairman, the Research Division is working together with the three $\mathrm{Ph} . \mathrm{D}$. scientists in the department (Drs. Freund, Scholl, and Vasilenko) and the clinical faculty to formalize this ongoing program. The primary goals of the Residents Research Program are to provide each resident with (1) an understanding of the benefits and problems of research through hands-on experiences and (2) the skills necessary to present a research paper to a professional audience. Although having research papers published in scholarly journals is a worthwhile goal, it is not a requirement of the program.

Residents are encouraged to base their own projects on the ongoing research interests and activities of the faculty. Residents can elect to participate on any of the following levels:

(1) Basic laboratory science investigations (for example, providing the clinical insight and human tissue specimens necessary for basic studies into the cause and treatment of disease)

(2) Clinical addenda to current studies (for example, follow-up examinations for the pregnant teenagers enrolled in Dr. Scholl's nutrition in adolescent pregnancy study or gynecologic examinations of nursing home residents to complement Dr. Belsky's survey study of nursing home health care practices)

(3) Analyses of clinical data already available from current studies (for example, the data on vomiting of pregnancy in teenagers which is available through Dr. Scholl's study)

(4) New drug, device, and other clinical trial studies (e.g., under the supervision of Michael B. Grossman, D.O., at the Obstetrics and Gynecology Ambulatory Care Clinic)

Past and current resident research projects in the Department of Obstetrics/Gynecology include:

(1) Cynthia Arkangel, D.O.-Morphometric analysis of heart sections of fetuses from diabetic rats (Faculty sponsor, Dr. Vasilenko)

(2) Howard Saul, D.O.--Safety and efficacy of nystatin suppositories versus miconazole and placebo in patients with vaginal candidiasis (Faculty sponsor, Dr. Grossman)

(3) Dr. Saul-Efficacy of 5 percent 5 -fluorouracil cream in the treatment of female genital condyloma (faculty sponsor, Dr. Grossman)

(4) David Goldberg D.O.-Mechanism of prostaglandin $\mathrm{F}_{2}$ alpha luteolysis in the Syrian (golden) hamster: possible role of an inhibitory factor (Faculty sponsor, Philip Chan, Ph.D.)

\section{d. Department of Obstetrics/Gynecology Journal Club}

Although the Journal Club meets monthly, every fourth month residents are assigned to present and discuss human research studies which are related to the laboratory and field research being performed by the Ph.D. scientists in the department. In this fashion, we are now stimulating residents to 
generate clinical research protocols that complement and build upon the foundation of basic work already being done at the school. The Division believes that this will make their research experiences more significant for their own future practice interests.

\section{e. Planned project}

Research collaborations with nursing schools and with the Department of Nursing at KMH/UMC and joint grant applications to the newly created $\mathrm{Na}$ tional Center for Nursing Research at NIH are being planned. The Department of Nursing at Rutgers University in Camden has agreed to work together with SOM in this area, too.

\section{Help from outside grant writers}

Medical writers/editors can help both new and experienced investigators to organize and prepare their written materials and thereby allow them more time to focus on scientific issues. However, grants do not pay for such help, and school or departmental seed money is usually required to fund this kind of approach.

\section{Use of other ancillary staff and support services and personnel}

\section{a. Research nurses}

The Departments of Medicine and Pediatrics each use a research nurse to help their faculty-investigators in performing clinical trial studies. The initial funds to hire such nurses (at least on a parttime basis) were obtained through the budgets for these studies which each investigator negotiated with the sponsor. Most clinical trial sponsors will routinely pay for a research nurse to help the principal investigator with various administrative aspects of the study. These might include preparing the documents needed for Institutional Review Board approval before the study can begin, screening office patients and informing them about the study and the opportunity for them to participate in it, completing individual case report forms, and scheduling subjects for study visits according to protocol. Over time, the Division anticipates that the successful record of clinical trials performance that research nurses help produce will result in the placement of larger and longer-term studies with clinical faculty-investigators.

\section{b. Research design and biostatistics consultants}

Dr. Steer consults with clinical faculty-investigators both within and outside of the Department of Psychiatry on research design, data base management, data analysis, and grant-writing issues. Dr. Scholl acts in a similar capacity for clinical faculty-investigators within the Department of Obstetrics/Gynecology.

\section{c. Biostatistics and grant-writing staff positions}

The Division is currently attempting to identify outside persons who are skilled in biostatistics (research design, data base management, data analysis, and related computer applications) or grantwriting to work with clinical faculty-investigators who want this kind of support. Modest institutional funds are now available for initial hiring (at least on a part-time basis), and the Division is attempting to identify sources of more permanent support to fund career positions. Over time, these positions may have the potential for faculty status, coterminous with funding to support them. Drs. Adelizzi and Vilensky have recently asked for help with this approach.

\section{Faculty research and research training fellowships at outside institutions}

The Division believes that it is appropriate to use school and/or departmental funds to help faculty who are committed to research careers in academic medicine to achieve their goals.

\section{Current example}

Dr. Bottalico, who recently completed his residency training in obstetrics/gynecology at SOM, has just finished a fellowship in maternal-fetal medicine at Pennsylvania Hospital in Philadelphia. On July 1, 1987, he was appointed to a faculty position in SOM's Department of Obstetrics/Gynecology. (In this case, however, Dr. Bottalico's fellowship was not supported with school or departmental funds.)

16. Clinical faculty release time dedicated for research activity and the recruitment and appointment of physicians to research faculty positions

\section{Financial incentive}

Each medical school or university has its own policy for the recovery of salary and indirect costs by 
faculty-investigators whose grants include these kinds of funds. SOM policies are as follows:

\section{a. Salary recoveries}

Bonus payments are made directly to a faculty member who is awarded a grant that supports a portion of his/her salary. Such payments are equal to one third of the grant support for a faculty member's salary up to a maximum of $\$ 5,000$ per fiscal year. Any remaining salary recoveries are placed in a departmental account for the investigator to use (with administrative overview by the department chairman) in further support of his/her research.

\section{b. Indirect cost recoveries}

These are a percentage of direct costs and are negotiated with each grantor or contractor. Approximately 15 percent of indirect costs from a grant are placed in a recovery account for the investigator to use (with administrative overview by the department chairman) in further support of his/her research. The remaining indirect cost recoveries are distributed at the state, university, medical school, and department levels; in some cases, department chairmen have passed their share back to the investigator's account.

\section{Participation on grant program advisory boards and/or scientific peer review panels}

Dr. Papa, for example, has served on the grant program committee of the New Jersey Affiliate of the American Heart Association, and Dr. Platt is a member of two National Institute on Drug Abuse panels: its AIDS Concept Review Committee and its Small Business Innovation Research grant program scientific peer review group. Also, Dr. Belsky is a current member of the Bureau of Research of the American Osteopathic Association, and Dr. Freund (associate dean for research) is currently vice chairman of the Bureau of Research Committee on Research Grants.

\section{Research collaborations with industry research and development scientists}

An example of such collaboration would be providing the clinical insights and human tissue specimens that may not otherwise be readily available to industry. The Research Division attempts to identify these kinds of opportunities in the same ways as described previously for consulting opportunities for clinical trials funded by the phar- maceutical and medical device industries (approach 2, b).

\section{a. Past projects}

(1) Dr. Adelizzi worked together with Human Medical Laboratories, Inc. (HML) of Cherry Hill, New Jersey, on a project to develop new immunodiagnostic tests for rheumatic diseases. He participated by referring patients with known connective tissue diseases to HML for plasmapheresis and subsequent study of obtained sera. (2) Dr. Vilensky worked together with a psychologic services consulting firm on the preparation of a proposal to develop training modules for law enforcement personnel on recognizing and managing alcohol and drug abusers. This proposal was intended for NIH's Small Business Innovation Research grant program.

\section{b. Current project}

Dr. Adelizzi, Dr. Vasilenko, Elizabeth O'Byrne, Ph.D. (Ciba-Geigy Corporation), and Ron Goldberg, Ph.D. (Ciba-Geigy Corporation) are jointly studying the effects of recombinant human interleukin-1 on human articular cartilage and chondrocytes and the pharmacologic modulation of these responses. Dr. Adelizzi is arranging for the human cartilage samples for this study (that is, cartilage that is normally discarded during joint replacement surgery), and he plans to join in publishing the research as well. In addition, the Division is negotiating a budget for the study with Ciba-Geigy which will pay for Dr. Adelizzi's research nurse to monitor the surgery schedule, harvest sterile samples from the surgeon in the operating room, and document patient histories.

\section{c. Planned projects}

(1) The Fetal Loss Program anticipates obtaining human fetal tissue specimens which it can supply to the pharmaceutical industry for study. This should be an attractive program for the industry since it normally does not have access to such material.

(2) Clinical faculty expressions of need based on their practice experience to which industry scientists can respond. As an example of this approach, a physician at UMDNJ-New Jersey Medical School expressed concern about reducing the incidence of infection with indwelling catheters. Through UMDNJ's patent lawyer, he was put in touch with interested industry scientists who subsequently 
developed a surfactant covering for catheters to which a variety of antibiotics can be bound permanently.

\section{Research and grant-writing collaborations}

Collaborations are made with Kennedy Memorial Hospitals/University Medical Center (KMH/ UMC), other local health care institutions and organizations, and local government agencies for research and grant-writing efforts.

\section{Past/current projects}

a. Dr. Cavalieri and Elyse Perweiler, R.N. (both Medicine) and KMH/UMC-Multidisciplinary geriatric assessment team

b. Dr. Finkel and KMH/UMC-Emergency room protocol for suspected cases of child sexual abuse

c. Dr. Grossman and Planned Parenthood/Greater Camden area-Through the Research Division, Dr. Grossman arranged for Institutional Review Board/Committee for the Protection of Human Subjects approval of a Planned Parenthood survey of its clients entitled "The sexually active adolescent woman's relationship with her partner: correlation with the couple's use of effective contraceptives."

d. Dr. Scholl and Camden County Health Department-Contract to evaluate Camden County adolescent pregnancy program.

\section{Research ideas and protocols generated from computerized medical records data bases}

Both Dr. Mochan (for the Department of Family Practice preceptor network) and Mark P. Jacobson, D.O. (Pediatrics) have discussed this approach with the Division. In addition, the Department of Psychiatry and the Division of Geriatrics (in the Department of Medicine) have been collaborating for several years on an integrated, computerized data base for the evaluation of their ongoing geropsychiatry service.

\section{Medical school research training modules}

This kind of approach involves accomplished faculty-investigators acting as mentors for newer researchers. Robert Rhoades, Ph.D. (Anatomy) anticipates acting as a mentor for an osteopathic phy- sician who is not a faculty member and who will become the first D.O./Ph.D candidate at SOM later this year.

\section{Interdepartmental collaboration for accrual of research subjects}

A current project of this nature involves Andrew D. deMasi, D.O. (Obstetrics/Gynecology). He is referring patients to Dr. Freed for his study of the role of iron replacement in the treatment and correction of idiopathic menorrhagia.

\section{Training for clinicians in philanthropic fund-raising}

This approach follows the successful model Drs. Freed, Papa, and Rothman have developed in the Department of Medicine. It is particularly useful for funding the evaluation of patient care and support programs (such as Dr. Freed's "Living Effectively With Cancer" program and Dr. Papa's cardiac rehabilitation program), since many public and private grant-making agencies do not give priority to support for this specialized kind of research activity.

\section{Comment}

The activation and support of clinical research at a college of osteopathic medicine, if it is to be productive, must be a planned phenomenon. It is best accomplished through a research development and coordinating office which helps the college administration to establish its long-term research priorities and works with individual facultyinvestigators to help them identify and address their own research goals and address them.

The most effective approach to activating clincial research is one that encourages physicians to build upon their ongoing clinical activities and insights. This approach is especially helpful because it allows each physician to begin activating that portion of his/her research program that is appropriate for the level of resources which may be available initially, while at the same time to work together with the research office to obtain the necessary outside support to upgrade and expand upon what he or she wants to accomplish. The research office, in turn, can be of help through one or more of the 24 ways to support physicians doing research that have been outlined. The physician-investigator and research 
office can pick and choose from them together on the basis of the college's particular operating circumstances and resources and the level of research and grant-seeking activity at which each physician-investigator wants to perform.

1. Herman, S.S. and Singer, A.M.: Basic scientists in clinical departments of medical schools. Clin Res 34:149-58, Apr 86

2. D'Alonzo, G.E.: Clinical research in osteopathic medicine. JAOA 87:440-5, Jun 87

3. Goldberg, G.: Motivating faculty grantseeking behaviors. Lessons learned and to be learned. Proceedings of Faculty Evaluation and De- velopment. Lessons learned. National Issues in Higher Education 22:119-27, Oct 86

4. Goldberg, G.: How we learned to ask sponsors for help (not money). J Soc Res Admin 16:17-22, Fall 1984

5. McKenzie, B.J.: Towards a more effective style of research administration: a comparison of the bureaucratic and adaptive styles. J Soc Res Admin 15:27-34, Summer 1983

Mr Goldberg is the director of the Research Division and an adjunct instructor, Department of Obstetrics and Gynecology, University of Medicine and Dentistry of New Jersey - School of Osteopathic Medicine.

Mr. Goldberg, UMDNJ-SOM, Research Division, 401 Haddon Avenue, Camden, New Jersey 08103. 